\title{
Reliability of thyroglobulin in serum compared with urinary iodine when assessing individual and population iodine nutrition status
}

\author{
Stig Andersen ${ }^{1,2,3 *}$, Paneeraq Noahsen ${ }^{1,4}$, Louise Westergaard ${ }^{2}$ and Peter Laurberg ${ }^{1,4}$ \\ ${ }^{1}$ Arctic Health Research Centre, Institute of Clinical Medicine, Aalborg University Hospital, 9000 Aalborg, Denmark \\ ${ }^{2}$ Department of Geriatric and Internal Medicine, Aalborg University Hospital, 9000 Aalborg, Denmark \\ ${ }^{3}$ Ilisimatusarfik, University of Greenland, 3400 Nuuk, Greenland \\ ${ }^{4}$ Department of Endocrinology, Aalborg University Hospital, 9000 Aalborg, Denmark \\ (Submitted 10 September 2016 - Final revision received 13 December 2016 - Accepted 3 January 2017- First published online 22 February 2017)
}

\section{Abstract}

The occurrence of thyroid disorders relies on I nutrition and monitoring of all populations is recommended. Measuring I in urine is standard but thyroglobulin in serum is an alternative. This led us to assess the reliability of studies using serum thyroglobulin compared with urinary I to assess the I nutrition level and calculate the number of participants needed in a study with repeated data sampling in the same individuals for 1 year. Diet, supplement use and life style factors were assessed by questionnaires. We measured thyroglobulin and thyroglobulin antibodies in serum and I in urine. Participants were thirty-three Caucasians and sixty-four Inuit living in Greenland aged 30-49 years. Serum thyroglobulin decreased with rising I excretion (Kendall's $\tau-0.29, P=0.005$ ) and did not differ with ethnicity. Variation in individuals was lower for serum-thyroglobulin than for urinary I (mean individual CV: $15 \cdot 1 v .46 \cdot 1 \% ; P<0 \cdot 01$ ). It required 245 urine samples to be $95 \%$ certain of having a urinary I excretion within $10 \%$ of the true mean of the population. For serum-thyroglobulin the same precision required 206 samples. In an individual ten times more samples were needed to depict I deficiency when using urinary I excretion compared with serum-thyroglobulin. In conclusion, more participants are need to portray I deficiency in a population when using urinary I compared with serum-thyroglobulin, and about ten times more samples are needed in an individual. Adding serum-thyroglobulin to urinary I may inform surveys of I nutrition by allowing subgroup analysis with similar reliability.

Key words: Thyroglobulin: Urinary iodine excretion: Number of samples needed: Reliability of iodine nutrition surveillance: Iodine nutrition study design

I nutrition is important and the World Health Organization ${ }^{(1)}$ recommends monitoring of all populations. Urinary iodine concentration (UIC) is a recommended method to assess I status in a population but it has limitations. First, it portrays the I intake over the preceding hours only ${ }^{(2-5)}$. Second, it holds uncertainties due to a marked variation in urinary I excretion ${ }^{(5,6)}$. Hence, a considerable number of individuals or samples are required for a reliable estimate of I nutrition level ${ }^{(7,8)}$. Alternative approaches to assess I nutrition include measurement of thyroglobulin in serum ${\text { (s-TG })^{(5,9-11)} \text { and thyroid volume by ultrasound }}^{(12,13)}$. They differ from UIC in that thyroid volume reflects the I status over the preceding years and it correlates positively to $s-\mathrm{TG}^{(14)}$.

TG is a protein produced exclusively by the thyroid gland. It plays an important role in the synthesis of thyroid hormones and an increased amount of TG is released into the blood in I deficiency ${ }^{(5,9-11)}$. Thus, s-TG is a sensitive marker of I deficiency in a population.

S-TG is used to monitor patients treated for differentiated thyroid cancer and the effectiveness is well established in this group of patients ${ }^{(15,16)}$. However, even though it is well recognised that $\mathrm{s}$-TG is elevated with I deficiency, data are lacking on the number of samples needed and on the reliability of s-TG as a measure of I deficiency. These measures are well established for urinary I excretion ${ }^{(7,8,17)}$ and similar estimates are relevant for $\mathrm{s}$-TG.

This led us to conduct a survey with repeated collection of serum and urine for measurement of s-TG and I in urine. Data were used to establish (a) the number of participants needed in surveys of I nutrition and (b) to calculate the reliability of studies of I nutrition by both s-TG and UIC with a given number of participants. Finally, we assessed the potential benefit of the combined use of both methods.

\section{Methods}

\section{Participants}

We enrolled ninety-seven healthy subjects living in Ilulissat or Saqqaq in the Disco Bay area in North Greenland. A random

Abbreviations: s-TG, serum thyroglobulin; TGAb, thyroglobulin antibodies; UIC, urinary iodine concentration.

* Corresponding author: Professor S. Andersen, email stiga@dadlnet.dk 
sample of individuals was drawn from the National Civil Registration System in which every person living in Denmark, the Faeroe Islands and Greenland is registered. Subjects invited to participate showed an interest in supporting the points raised and agreed to contribute. In all, eighty-five out of ninety-seven (88\%) participated in three or four of the data collections. Participants in Ilulissat were stratified by age, sex and place of birth to approximate equal participation in the age groups 30-39 and 40-49 years, men and women, and the three groups consisting of (a) subjects not born in Greenland, (b) subjects born in Greenland living in town and (c) in a settlement. Subjects with both parents born in Greenland are hereafter named Inuit, and subjects whose parents are both born outside Greenland are named Caucasians.

\section{Procedures}

Data were collected four times during a full year to include also seasonal differences in the estimate of individual variance (30 March through 10 April, 25 June through 5 July, 25 September through 5 October and 7 January through 19 January).

Participants were invited by letter to participate in the investigation. The investigation took place at the local hospital or nursing station or, at request, as home visits.

A physical examination was performed by one of the doctors collecting data (S. A., P. L.). We measured height and weight in indoor clothing, calculated BMI(weight in kilograms divided by height in metres squared) and recorded if any disability was present. Information on smoking habits (present/past/never), alcohol intake (units/week), use of I containing supplements and medication was obtained by a questionnaire. None took medication containing I or known to influence the thyroid. Information regarding sex and age was obtained from the National Civil Registration System.

Information on dietary habits was obtained by a FFQ as described previously ${ }^{(18)}$. In brief, the frequency of intake of seven traditional Inuit food items and seven imported food items were given in six categories ranging from never to daily. Inuit food items scored positively and imported food items scored negatively. The sum of food frequency score for all food items consumed by each participant was calculated based on this recording and participants were categorised into groups of intake of $<40,40-60$ and $>60 \%$ traditional Inuit food items scores on a scale where $100 \%$ was purely Inuit foods and $0 \%$ was purely imported food. Moreover, participants were asked how many days of the week the main meal was of Greenlandic food items and the number of days it was imported foods for cross-validation

A non-fasting blood sample was drawn from the antecubital vein using minimal tourniquet. Blood was allowed to clot and serum was separated and kept at $-20^{\circ} \mathrm{C}$ until analysis. A spot urine sample was collected in I-free polyethylene containers and stored at $-20^{\circ} \mathrm{C}$ until analysis.

Ethical approval was obtained from the Commission for Scientific Research in Greenland before the commencement of this study (505-63), and all subjects gave informed written consent in Danish or Greenlandic by participant choice.
Assays

TG was measured in serum by the LUMItest (BRAHMS) that had a working range of $1-500 \mu \mathrm{g} / \mathrm{l}$. All samples from an individual were included in the same assay run. Median values about 9, 10 and $15 \mu \mathrm{g} / 1$ are seen in I replete, mildly deficient and moderately deficient Caucasians, respectively ${ }^{(9,10)}$. Thyroglobulin antibodies (TGAb) were measured using Dynotest RIA (BRAHMS Diagnostica) with a functional sensitivity of $20 \mathrm{kU} / \mathrm{l}$. TGAb in serum did not influence measurement of s-TG when $<100 \mathrm{U} / \mathrm{ml}$ and all individuals with $\mathrm{TGAb}<100 \mathrm{U} / \mathrm{ml}$ were included in the analysis. Thus, eighty-one participants were included in the analysis including s-TG.

Urine samples were analysed for I by using the SandellKolthoff reaction modified after Wilson \& van $\mathrm{Zyl}^{(19)}$ as described in detail previously ${ }^{(18,20)}$.

\section{Statistics and calculations}

Population characteristics were compared using Mann-Whitney $U$ test for comparison of two groups. Kendall's $\tau$ was used to describe associations between groups. Frequencies were compared using Fisher's exact test or $\chi^{2}$ test with groups of less than five participants included in the adjacent group when appropriate.

The number of samples needed to assess the I status of a population or an individual was calculated from the equation developed to estimate the precision of a set-point, $D$, in biochemical variables ${ }^{(21)}: n=(Z \times C V \% / D)^{2}$. Similar calculations are recommended for use when estimating the number of specimens required in biochemical measures. This provides an estimate of the certainty or reliability of the results of sample collections. It is described in detail by Fraser \& Harris ${ }^{(21)}$ and we followed these recommendations in keeping with our previous reports on urinary I in different populations ${ }^{(7,8)}$. The percentiles of standard normal distribution $(Z)$ used were 2.58 for $99 \%$, 2.33 for $98 \%, 1.96$ for $95 \%, 1.64$ for $90 \%, 1.28$ for $80 \%, 1.04$ for $70 \%, 0.84$ for $60 \%, 0.67$ for $50 \%$. The precision range $(D)$, a measure of reliability of the assessment of I nutrition level, used in the calculations was set to vary from \pm 50 to $\pm 1 \%$. Using the $z$-statistics may underestimate the sample size for small $n$ by up to $30 \%$ compared with using $t$-statistics but this was chosen in order to comply with the recommendations as noted above ${ }^{(7)}$. Mean within-individual variances were similar whether assessed as the mean variance among individual or using ANOVA techniques. Mean, highest and lowest withinindividual CV was used for calculation of number of samples needed to assess the I excretion in an individual. The CV\% was the percentage of variance square root divided by the mean. Variances were compared by Levene's test for homogeneity of variances.

The statistical program for the social sciences version 13.0, Corel Quattro Pro X3 and a Texas Instruments TI-30X IIS calculator were used to process data and perform the calculations.

\section{Results}

Totally, ninety-seven participants were enrolled with thirtythree Caucasians, thirty-nine Inuit in the town Ilulissat and 
Table 1. Subjects enrolled in the study of reliability of measures of population iodine deficiency and of number of subjects neededt (Numbers and percentages; medians and interquartile ranges (IQR); mean values and standard deviations)

\begin{tabular}{|c|c|c|c|c|c|c|c|}
\hline & \multicolumn{2}{|c|}{ All participants } & \multicolumn{2}{|c|}{ Caucasians } & \multicolumn{2}{|c|}{ Inuit } & \multirow[b]{2}{*}{$P^{\star}$} \\
\hline & $n$ & $\%$ & $n$ & $\%$ & $n$ & $\%$ & \\
\hline & 97 & 100 & 33 & 34.0 & 64 & $66 \cdot 0$ & \\
\hline Age (years) & & & & & & & NS \\
\hline $30-39$ & 55 & $56 \cdot 7$ & 21 & 63.6 & 34 & 53.1 & \\
\hline $40-49$ & 42 & $43 \cdot 3$ & 12 & 36.4 & 30 & $46 \cdot 9$ & \\
\hline Sex & & & & & & & NS \\
\hline Men & 48 & 49.5 & 18 & 54.5 & 30 & $46 \cdot 9$ & \\
\hline Women & 49 & 50.5 & 15 & 45.5 & 34 & $53 \cdot 1$ & \\
\hline BMI $\left(\mathrm{kg} / \mathrm{m}^{2}\right)$ & & & & & & & NS \\
\hline$<18.5$ & 1 & $1 \cdot 1$ & 0 & 0.0 & 1 & 1.6 & \\
\hline $18 \cdot 5-25$ & 39 & $41 \cdot 1$ & 15 & 45.5 & 24 & $38 \cdot 7$ & \\
\hline $25-30$ & 34 & $35 \cdot 8$ & 11 & 33.3 & 23 & $37 \cdot 1$ & \\
\hline $30+$ & 21 & $22 \cdot 1$ & 7 & $21 \cdot 2$ & 14 & $22 \cdot 6$ & \\
\hline Inuit dietł & & & & & & & 0.004 \\
\hline$<40 \%$ & 67 & $69 \cdot 1$ & 29 & 87.8 & 38 & 59.4 & \\
\hline $40-60 \%$ & 29 & 29.9 & 4 & $12 \cdot 1$ & 25 & 39.1 & \\
\hline $60+\%$ & 1 & 1.0 & 0 & 0.0 & 1 & 1.6 & \\
\hline \multicolumn{8}{|l|}{ Smoker§ } \\
\hline Present & 50 & $52 \cdot 6$ & 12 & 37.5 & 38 & $60 \cdot 3$ & 0.054 \\
\hline Past & 15 & $15 \cdot 8$ & 5 & $15 \cdot 6$ & 10 & $15 \cdot 9$ & \\
\hline Never & 30 & $31 \cdot 6$ & 15 & $46 \cdot 9$ & 15 & $23 \cdot 8$ & \\
\hline Alcohol $\| \boldsymbol{\Phi}$ & & & & & & & 0.029 \\
\hline Abstainers & 17 & $17 \cdot 5$ & 1 & 3.1 & 16 & $25 \cdot 8$ & \\
\hline$<7$ units/week & 69 & $73 \cdot 4$ & 27 & 84.4 & 25 & $40 \cdot 3$ & \\
\hline 7+ units/week & 25 & $26 \cdot 6$ & 4 & 12.5 & 21 & 33.9 & \\
\hline Data collections ${ }^{\star *}$ & & & & & & & NS \\
\hline$<3$ & 12 & $12 \cdot 4$ & 3 & $9 \cdot 1$ & 9 & $14 \cdot 1$ & \\
\hline 3 or 4 & 85 & 97.6 & 30 & $90 \cdot 9$ & 55 & 85.9 & \\
\hline 4 & 73 & $75 \cdot 3$ & 27 & $81 \cdot 8$ & 46 & 71.9 & \\
\hline \multicolumn{8}{|l|}{ TGAb (U/ml) } \\
\hline$>20+\dagger$ & 29 & $32 \cdot 2$ & 10 & $30 \cdot 3$ & 19 & $33 \cdot 3$ & NS \\
\hline$>100 \ddagger \ddagger$ & 5 & $5 \cdot 2$ & 1 & 3.0 & 4 & $6 \cdot 3$ & \\
\hline \multicolumn{8}{|l|}{ Urinary I ( $\mu \mathrm{g} / \mathrm{l})$} \\
\hline Median & \multicolumn{2}{|c|}{87} & \multicolumn{2}{|c|}{78} & \multicolumn{2}{|c|}{88} & 0.036 \\
\hline IQR & \multicolumn{2}{|c|}{72} & \multicolumn{2}{|c|}{66} & \multicolumn{2}{|c|}{82} & \\
\hline Mean & \multicolumn{2}{|c|}{116} & \multicolumn{2}{|c|}{103} & \multicolumn{2}{|c|}{128} & \\
\hline SD & \multicolumn{2}{|c|}{96} & \multicolumn{2}{|c|}{84} & \multicolumn{2}{|c|}{136} & \\
\hline
\end{tabular}

TGAb, thyroglobulin antibodies.

* $P$ value for ethnic differences: $\chi^{2}$ test, except alcohol that was tested using Fisher's exact test and urinary I using Mann-Whitney test; NS designates $P>0.1$. Groups with less than five participants were merged with adjacent groups (BMl $<25 \mathrm{~kg} / \mathrm{m}^{2}$; Inuit diet scores $<40 \%$; alcohol $<7 \mathrm{units} / \mathrm{week}$; less than four data collections).

t Of the 97 subjects enrolled, eighty-one were included in the calculations as they participated in three or four data collections and did not have antibodies against thyroglobulin that could influence the measurement of thyroglobulin.

‡ Calculated from a FFQ on the intake of seven Greenlandic and seven imported food items.

$\S 2$ missing.

|| 4 missing.

Tl One unit equals $2 \mathrm{~g}$ of alcohol.

${ }_{* *}$ Number of participations in data collection with questionnaire and collection of specimens.

†† Level for positive thyroglobulin antibody as given by the manufacturer.

拉 Serum TG was influenced only when TGAb was above 100.

twenty-five Inuit in the settlement Saqqaq (Table 1). None of the participants had disease affecting the thyroid, were pregnant or took I-containing supplements. The number of subjects participating in four, three, two and one data collection was seventy-three, twelve, nine and three. Participants who attended less than three times ( $n$ 12) and participants who had TGAb that could affect the measurement of s-TG $(n 5)$ were excluded from the calculations. The calculations thus included eighty-one subjects.

Caucasians were bigger than Inuit (men/women, height $P<0 \cdot 001 / P<0.001$; weight $P=0 \cdot 01 / P=0 \cdot 026)$. Still, BMI was similar (Table 1). Height, weight and BMI did not differ with residence or age (residence, all, $P>0 \cdot 1$; age in Caucasians, all, $P>0.1$; age in Inuit, women's height, $P=0.054$, all other $P>0 \cdot 1)$. Dietary habits differed with ethnicity, and more Inuit than Caucasians were smokers and alcohol abstainers. Inuit had slightly higher urinary I excretion (Table 1).

The frequency of TGAb positive individuals did not differ with ethnicity (Table 1). Median s-TG did not differ with ethnicity $(P=0 \cdot 70)$. S-TG was higher when UIC was $<50 \mu \mathrm{g} / \mathrm{l}$, and the frequency of $s-\mathrm{TG}>20 \mu \mathrm{g} / \mathrm{l}$ decreased with rising UIC (Kendall's $\tau-0 \cdot 29, P=0 \cdot 005$ ) (Fig. 1). 


\section{Variation}

Table 2 shows mean, variance and CV\% for s-TG and UIC among Inuit and Caucasians. Overall, between individual, mean individual and median individual variation was higher in Inuit compared with Caucasians. Overall variation was higher in UIC compared with s-TG $(P<0.01)$ and the two measures of individual variation were markedly higher for UIC compared with s-TG (Table 2).

\section{Number of samples needed}

Table 3 lists the number of samples need for a chosen precision range of $1-50 \%$ with a confidence of $95 \%$. This is shown both for an individual (right columns) and for populations (left column). It can be seen that 982 subjects need to donate one sample each to be $95 \%$ certain of having a UIC within $5 \%$ of the true mean of that population. For $s$-TG the same precision

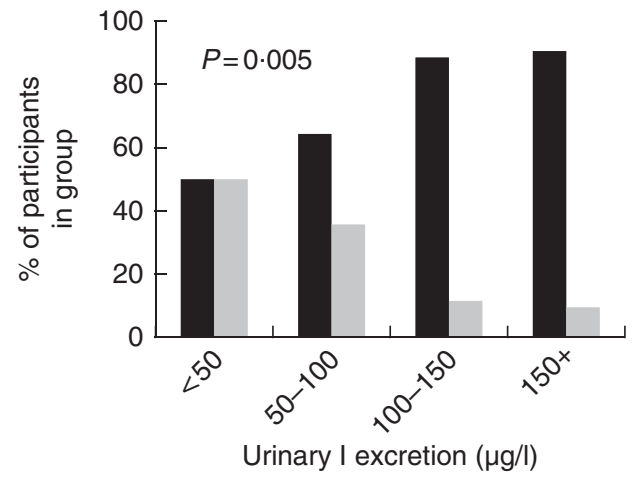

Fig. 1. The frequency of thyroglobulin (TG) in serum above or below $20 \mu \mathrm{g} / \mathrm{l}$ is illustrated for different levels of urinary iodine excretion. The frequency of $\mathrm{s}-\mathrm{TG}>20 \mu \mathrm{g} / \mathrm{l}$ decreased with rising urinary iodine excretion (Kendall's $\tau$, $P=0.005)$. $\square, \mathrm{TG}<20 \mu \mathrm{g} / \mathrm{l} ; \square, 20>\mu \mathrm{g} / \mathrm{l}$. requires 823 subjects. As can be read from Table 3, 20\% more participants are needed to portray I deficiency in a population using UIC compared with s-TG.

For an individual, the results of two samples gives a precision range of $20 \%$ when using s-TG, whereas the same precision range for UIC requires twenty-one urine samples from that individual. In addition, a single blood sample for s-TG measurement in an individual gives a precision of $30 \% \mathrm{CI}$, whereas nine urine samples are need from that individual to match this precision with $95 \% \mathrm{CI}$. The difference between individuals in variation for s-TG is lower than that found for urinary I.

Table 4 lists the number of samples needed in an individual (right column) and the number of participants needed in population surveys (left column) to detect I deficiency when the $\mathrm{CI}$ is chosen to vary in parallel with the precision range. In a population, a $10 \%$ precision with $90 \%$ CI requires 144 participants for s-TG and 172 participants for urinary I excretion. A precision range of $2 \%$ with $98 \%$ CI requires 7268 participants for s-TG and 8669 participants for urinary I analysis. Thus, 20\% more participants are needed to settle I deficiency when using UIC compared with s-TG.

For an individual, a precision range of $20 \%$ with $80 \% \mathrm{CI}$ requires a single sample for s-TG and nine samples for UIC. A precision range of $10 \%$ with $90 \%$ CI requires six blood samples for s-TG and fifty-eight urine samples for UIC. Thus, just under ten times more urine samples are needed in an individual to depict I deficiency when using urinary I excretion compared with measurement of s-TG.

\section{Reliability of surveys}

The reliability of studies of I nutrition can be read from the $x$-axis in Fig. 2 matching a specified number of participants on the $y$-axis. The upper panel illustrates that about ten times more urine samples are needed compared with serum to obtain a

Table 2. Participants' descriptive and variation in thyroglobulin in serum and iodine in urine in eighty-one participants who participated in at least three data collections and had thyroglobulin antibodies $<100 \mathrm{U} / \mathrm{ml}$

\begin{tabular}{|c|c|c|c|c|c|c|c|c|}
\hline & \multirow{2}{*}{$\frac{\text { Age }}{\text { Mean (years) }}$} & \multirow{2}{*}{$\frac{\mathrm{BMI}}{\text { Mean }\left(\mathrm{kg} / \mathrm{m}^{2}\right)}$} & \multicolumn{3}{|c|}{ Thyroglobulin in serum $(\mu \mathrm{g} / \mathrm{l})$} & \multicolumn{3}{|c|}{ I content in urine $(\mu \mathrm{g} / \mathrm{l})$} \\
\hline & & & Mean* & Variance $^{*}$ & $\mathrm{CV} \%{ }^{*} \dagger$ & Mean* & Variance $^{*}$ & $C V \%{ }^{*} \dagger$ \\
\hline Inuit & $39 \cdot 6$ & $26 \cdot 8$ & & & & & & \\
\hline Overall & & & 14.4 & 114.9 & 74.2 & $128 \cdot 3$ & 18446 & 128.4 \\
\hline Between individual & & & 14.4 & 114.5 & $74 \cdot 1 \ddagger$ & $128 \cdot 4$ & 17520 & $95 \cdot 6 \neq$ \\
\hline Mean individual & & & 14.5 & $17 \cdot 0$ & 22.7 & 129.0 & 13308 & 59.4 \\
\hline Median individual & & & 11.5 & $2 \cdot 2$ & 14.5 & 118.5 & 1774 & $51 \cdot 1$ \\
\hline Caucasians & $39 \cdot 3$ & $26 \cdot 8$ & & & & & & \\
\hline Overall & & & 11.6 & $60 \cdot 8$ & $66 \cdot 9$ & 102.7 & 6990 & 81.4 \\
\hline Between individual & & & 11.6 & 59.5 & $65 \cdot 0 \ddagger$ & $102 \cdot 9$ & 6590 & $76 \cdot 3 \ddagger$ \\
\hline Mean individual & & & 11.6 & $6 \cdot 0$ & $16 \cdot 6$ & $101 \cdot 7$ & 4044 & $48 \cdot 7$ \\
\hline Median individual & & & $10 \cdot 4$ & 1.3 & $15 \cdot 5$ & $91 \cdot 1$ & 1321 & 44.4 \\
\hline All participants & 39.5 & $26 \cdot 8$ & & & & & & \\
\hline Overall & & & 13.5 & 98.7 & 73.5 & $115 \cdot 6$ & 9293 & 83.4 \\
\hline Between individual & & & 13.5 & $98 \cdot 1$ & $73 \cdot 2 \ddagger$ & $115 \cdot 7$ & 8954 & $79.9 \ddagger$ \\
\hline Mean individual & & & $13 \cdot 6$ & $13 \cdot 4$ & $20 \cdot 9$ & $116 \cdot 1$ & 5859 & 53.7 \\
\hline Median individual & & & 11.4 & 1.9 & $15 \cdot 1$ & 106.9 & 1496 & $46 \cdot 5$ \\
\hline
\end{tabular}

* Based on three or four samples in each of eighty-one participants.

† Calculated as $\left(\Sigma_{\mathrm{CV}} \%_{1-n}^{2}\right)^{1 / 2}$. Calculations using ANOVA techniques gave similar results.

$\ddagger$ Square root of sum of squared CV for each data collection: $\left(\Sigma \mathrm{CV} \%_{1-n}^{2}\right)^{1 / 2}$. 
Table 3. Number of participants needed to be $95 \%$ confident of being within a specified range for serum thyroglobulin (TG) to describe the I nutrition status of a population (Numbers; median, lowest and highest variations)

\begin{tabular}{|c|c|c|c|c|c|c|c|c|}
\hline \multirow[b]{4}{*}{$\begin{array}{l}\text { Precision range } \\
(\%) \S\end{array}$} & \multicolumn{8}{|c|}{ Number of samples needed for estimation of I deficiency with a specified precision range ${ }^{*}$} \\
\hline & \multicolumn{4}{|c|}{ Serum thyroglobulin $(\mu \mathrm{g} / \mathrm{l})$} & \multicolumn{4}{|c|}{ Urinary I concentration $(\mu \mathrm{g} / \mathrm{l})$} \\
\hline & \multirow{2}{*}{ 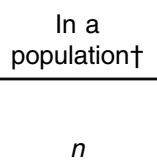 } & \multicolumn{3}{|c|}{ In an individualł } & \multirow{2}{*}{$\begin{array}{c}\begin{array}{c}\text { In a } \\
\text { populationt }\end{array} \\
n\end{array}$} & \multicolumn{3}{|c|}{ In an individualł } \\
\hline & & $\begin{array}{c}\text { Median } \\
\text { variation }\end{array}$ & Lowest & $\begin{array}{c}\text { Highest } \\
\text { variation }\end{array}$ & & $\begin{array}{c}\text { Median } \\
\text { variation }\end{array}$ & Lowest & $\begin{array}{c}\text { Highest } \\
\text { variation }\end{array}$ \\
\hline \pm 1 & 20572 & 877 & 13 & 40736 & 24593 & 8295 & 86 & 58724 \\
\hline \pm 2 & 5143 & 219 & 3 & 10184 & 6135 & 2074 & 21 & 14681 \\
\hline \pm 5 & 823 & 35 & 1 & 1629 & 982 & 332 & 3 & 2349 \\
\hline \pm 10 & 206 & 9 & 1 & 407 & 245 & 83 & 1 & 587 \\
\hline \pm 20 & 51 & 2 & 1 & 102 & 61 & 21 & 1 & 147 \\
\hline \pm 30 & 23 & 1 & 1 & 45 & 27 & 9 & 1 & 65 \\
\hline \pm 40 & 13 & 1 & 1 & 25 & 15 & 5 & 1 & 37 \\
\hline \pm 50 & 8 & 1 & 1 & 16 & 10 & 3 & 1 & 23 \\
\hline
\end{tabular}

similar reliability in an individual. The lower panel shows that $20 \%$ more urine samples are needed in a population. The logarithmic scale on the $y$-axis illustrates the steep rise in the number of participants required when the reliability of I nutrition studies is increased.

\section{Discussion}

I deficiency may cause a spectrum of disorders that can be prevented by cheap and simple I supplementation ${ }^{(22)}$. Identification of I-deficient populations and monitoring of I fortification programmes are done by population surveys ${ }^{(18,23-25)}$, and collection of urine samples for measuring I excretion is the standard method. However, this method has two major limitations. First, I is excreted within hours after ingestion and urinary I thus represents I intake only over the preceding hours ${ }^{(2-5)}$ and spot urine samples may underestimate the true I excretion in populations with I-rich main meals ${ }^{(26)}$. The thyroid has the capacity to store large amounts of I and the urinary I excretion may thus not represent the true I intake level in I-deficient populations ${ }^{(6,7)}$. Second, I excretion varies considerably due to both differences in diet and due to dilution depending on the fluid intake, perspiration, ambient temperature and other factors $^{(5,6)}$. This marked variation causes a considerable number of samples to be required for a reliable estimate of the true I nutrition level of that population or individual ${ }^{(7,8,17)}$. Both of these issues are addressed by the use of TG in serum.

$\mathrm{S}$-TG is used to monitor patients treated for differentiated thyroid cancer by detection of low levels of s-TG. Elevated s-TG is seen with sustained I deficiency and it has been suggested and used in surveys of I nutrition ${ }^{(9-11,27)}$. The present study provides the first data to describe the reliability of surveys using s-TG to assess and monitor I nutrition. In addition, we calculated the number of samples needed for a certain level of confidence in the
I nutrition level estimated. Similar data have been published for urinary I excretion $^{(7,8,17)}$ and we included data on UIC in the present study to allow for direct comparisons.

\section{Reliability of iodine nutrition studies}

We found a slightly lower between-individual variation for s-TG compared with UIC providing an advantage to s-TG over UIC in population surveys. Thus, $20 \%$ more samples are needed for the same precision when using UIC as compared with s-TG. For example, if a precision of $5 \%$ is aimed for, a survey requires one sample from each of 823 individuals when measuring s-TG and one sample from each of 982 individuals when measuring UIC. Conversely, if 1000 subjects are surveyed then the result is within $\pm 4.5 \%$ of the true value for s-TG and $\pm 5.0 \%$ for UIC. If 100 participants are included then this precision range is $14 \%$ for s-TG and $16 \%$ for UIC with $95 \%$ CI. In other words, a mean value of 100 suggests that the true population mean is between 86 and 114 for s-TG and between 84 and 116 for UIC in the example.

Within-individual variation is much lower for s-TG than for UIC. Consequently, the number of samples needed in an individual is much lower and about ten times more samples are needed for the same precision when using UIC as compared with s-TG. It takes twenty-one urine samples to obtain a precision of $\pm 20 \%$, whereas this is seen with just two measurements of s-TG. Thus, ten times more samples are needed in an individual for the same reliability of the results when comparing UIC with s-TG.

The risk of error is lower for s-TG compared with UIC. The importance of number of samples for the risk of error can be estimated by comparing Tables 3 and 4 . A $90 \%$ confidence of being within $10 \%$ from the true I nutrition level requires 6 (33) less samples for s-TG (UIC) than a $95 \%$ CI of being within $10 \%$ from the actual level. 

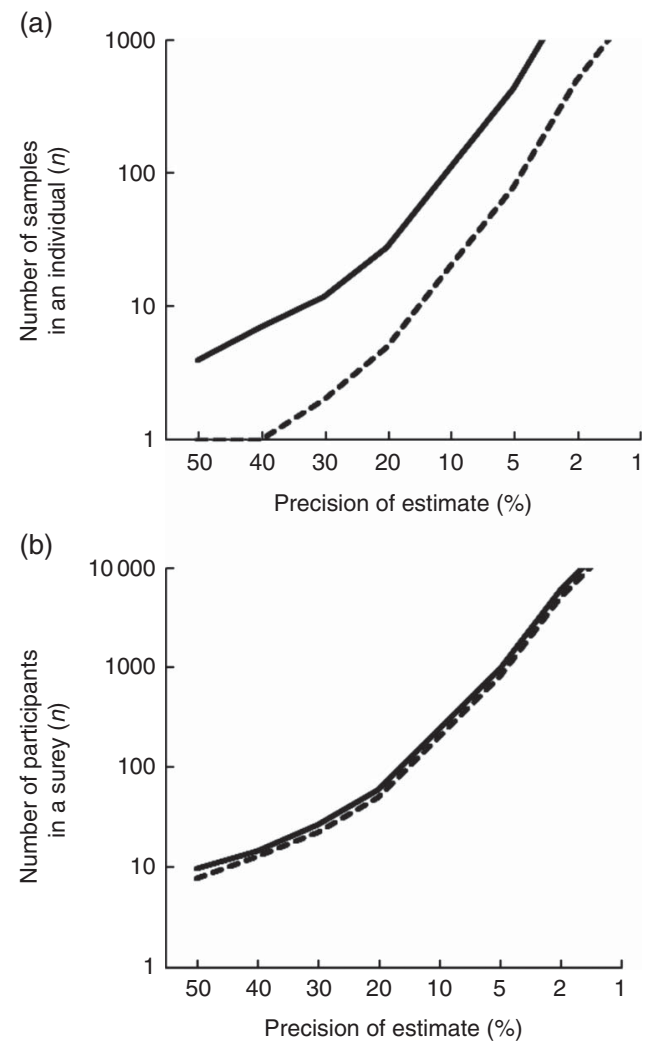

Fig. 2. The relation between number of participants and the precision of the estimate of iodine nutrition by both thyroglobulin ( $\mathrm{TG},----)$ and urinary iodine excretion (UIC, $\longrightarrow$ ). The precision of studies of iodine nutrition $(x$-axis) and the corresponding number of participants needed ( $y$-axis) for that specific precision. About ten times more urine samples are needed compared with serum to obtain a similar precision in an individual (a) while $20 \%$ more samples are needed in a population (b). The logarithmic scale on the $y$-axis illustrates the marked decrease in the number of participants required when lowering the demand for precision in iodine nutrition studies.

The variance found for urinary I was high, similar to previous studies of variation in urinary I excretion ${ }^{(7,8,17)}$. This is comparable across populations ${ }^{(7,17)}$, I excretion levels ${ }^{(7,8)}$ and after initiation of an I fortification programme ${ }^{(8)}$. This reinforces the reliability of the results of these studies of variation and reliability that support design of future I nutrition studies.

\section{Design of iodine nutrition studies}

Urinary I portrays the I intake during the hours before sampling while s-TG is rather a measure of long-term I nutrition ${ }^{(10,28)}$. The two measures of I nutrition thus provide information on different aspects of the I nutrition level of the population surveyed. The two measures combined could provide a more detailed description of the true I nutrition level of a population. Moreover, the use of both measures could be speculated to be a more accurate predictor of I deficiency disorders than the single measure of UIC. Thus, the combined UIC and s-TG could provide a two-dimensional insight into I nutrition level of a population. A description of the importance of variation of both of these measures is available from this study and may guide an intelligent study design.

The intelligent study design would seek to benefit from the advantages of each of the two measures. We suggest first to 
assess the nutrition level from UIC and subsequently to add details and subgroup analysis within that population by the use of s-TG.

For example, we aimed for a precision of $5 \%$ in an I nutrition survey. First, we need to survey 982 participants to be $95 \%$ sure of this precision for UIC. The confirmation and subgroup analysis by the use of s-TG requires $823,20 \%$ less participants, and the precision would still be $5 \%$. Thus, the combined use of UIC and s-TG allows for further analysis with unaltered validity of the estimates.

Populations may be heterogeneous. They may cover different geographical areas with different subsurface geology ${ }^{(28,29)}$, differences in water supply, differences in dietary habits ${ }^{(18,30)}$ or different ethnic groups that call for subgroup analysis. The I nutrition level should be assessed for each of such groups and our data guide the analysis if s-TG is used.

\section{Level of serum thyroglobulin}

A cut-off level for s-TG has to be decided upon. S-TG concentrations were between 5 and $14 \mu \mathrm{g} / 1$ in healthy adults $^{(9,10,14,31,32)}$ and between 94 and $208 \mu \mathrm{g} / \mathrm{l}$ in adults in an area with endemic goitre ${ }^{(33,34)}$. A s-TG cut-off of $13 \mu \mathrm{g} / \mathrm{l}$ was suggested for children but it should not be concluded that this is a suitable level for I status in adults ${ }^{(35)}$.

The occurrence of s-TG above a cut-off level of $40 \mu \mathrm{g} / \mathrm{l}$ was used to delineate I deficiency in children ${ }^{(11)}$ and adults ${ }^{(10)}$. This contrasted the cut-off level of $13 \mu \mathrm{g} / \mathrm{l}$ reported to be the median value that delineated I-deficient adults ${ }^{(35)}$. The authors of the latter review emphasised the need for further investigation to settle a cut-off level ${ }^{(35)}$. A recent randomised trial reported a median s-TG of $16.6 \mu \mathrm{g} / \mathrm{l}$ in adults with mild I deficiency and a decrease in s-TG with I supplementation ${ }^{(36)}$. In our population the overall mean level was $13.5 \mu \mathrm{g} / \mathrm{l}$ and the individual median was $11.5 \mu \mathrm{g} / \mathrm{l}$. The cut-off for I deficiency may be set to detect those with raised values rather than just above the median value. Thus, the 75 th-percentile in our population of $19.1 \mu \mathrm{g} / \mathrm{l}$ guided the level of $20 \mu \mathrm{g} / \mathrm{l}$ set to delineate individuals with I deficiency in our investigation. In addition, this was in between previous suggestions ${ }^{(9,10,14,29,31,35)}$ and provided a distinct separation of I deficiency groups in our data. It may thus be suggested to use this level to delineate I deficiency in an adult population.

\section{Limitations}

Serum concentration of TG has limitations. It is not specific for I deficiency but increases also with excess I intake, increasing thyroid mass, inflammation of the thyroid, cold, if the TSH receptor is stimulated and in pregnancy ${ }^{(23,37-41)}$. These groups should be identified and excluded or taken into consideration and corrected for in surveys of I deficiency using s-TG.

The use of s-TG should also consider inter-assay differences and possibly detection differences in s-TG between I nutrition levels. Attempts have been made to reduce the consequences thereof by standardisation ${ }^{(42)}$ but differences between assays remain and should be taken into consideration ${ }^{(10,42)}$. Hence, we suggest a two dimensional approach that includes I in urine for the overall assessment of I nutrition and s-TG for validation and individual I nutrition assessment. The results will thus be reliable based on UIC and supported by using s-TG.

The spot urine I excretion of our study population suggested borderline to mild I deficiency. Different I intake levels associate with different s-TG levels. Whether variance of s-TG also differs with levels of s-TG remains to be settled. Also, the variance for other groups such as school children needs to be clarified.

\section{Conclusion}

Variation was lower for s-TG than for UIC. Thus, more participants are needed for similar reliability of the results for UIC compared with s-TG. Consequently, $80 \%$ of samples are redundant in an individual if s-TG is used to assess I nutrition level, and $20 \%$ less individuals are needed in a population when using s-TG rather than UIC. Consequently, s-TG provides the opportunity for either fewer participants or a higher reliability.

This difference may be used to gain more from I nutrition surveys. The reliability of the study is upheld when UIC is used to assess the overall I nutrition level and s-TG is added to assess I nutrition in subgroups. This is important when planning and evaluating I nutrition surveys in populations and in individuals. We thus suggest using both measures to assess I nutrition in a smart I nutrition survey design.

\section{Acknowledgements}

The authors gratefully acknowledge Carla Hame and Ruth Møller Jensen for their support during the data collection in Saqqaq and Eskild Boeskov for support in Ilulissat.

This work was supported by grants from Greenland Government's Research Council and by Karen Elise Jensen Fond. They had no role in the design, analysis or writing of this article.

S. A. contributed to study design, raising of funds, data collection, analysis and interpretation of data and writing of the manuscript. P. N. contributed substantially to interpretation of data and critical review of the manuscript. L. W. contributed substantially to interpretation of data and critical review of the manuscript. P. L. contributed to study design, raising of funds, data collection, analysis and interpretation of data and reviewing of the manuscript. P. L. tragically passed away but did approve the final version of the manuscript before the initial review.

The authors declare that there are no conflicts of interest.

\section{References}

1. World Health Organization (2007) Assessment of Iodine Deficiency Disorders and Monitoring their Elimination: A Guide for Programme Managers, 3rd ed. WHO/UNICEF/ ICCIDD. Geneva: WHO.

2. Keating FR \& Albert A (1949) The metabolism of iodine in man as disclosed with the use of radioiodine. Rec Prog Horm Res $\mathbf{4}$, 429-481.

3. Vought RL, London WT, Lutwak L, et al. (1963) Reliability of estimates of serum inorganic iodine and daily fecal and urinary iodine excretion from single casual specimens. J Clin Endocrinol Metab 23, 1218-1228. 
4. Als C, Helbling A, Peter K, et al. (2000) Urinary iodine concentration follows a circadian rhythm: a study with 3023 spot urine samples in adults and children. J Clin Endocrinol Metab 85, 1367-1369.

5. Pearce EN \& Caldwell KL (2016) Urinary iodine, thyroid function, and thyroglobulin as biomarkers of iodine status. $\mathrm{Am}$ J Clin Nutr 104, 898S-901S.

6. Andersen S, Pedersen KM, Pedersen IB, et al. (2001) Variations in urinary iodine excretion and thyroid function. A 1-year study in healthy men. Eur J Endocrinol 144, 461-465.

7. Andersen S, Karmisholt J, Pedersen KM, et al. (2008) Reliability of studies of iodine intake and recommendations for number of samples in groups and in individuals. BrJ Nutr 99 , 813-818.

8. Karmisholt J, Laurberg P \& Andersen S (2014) Recommended number of participants in iodine nutrition studies is similar before and after an iodine fortification programme. Eur J Nutr 53, 487-492.

9. Knudsen N, Bülow I, Jørgensen T, et al. (2001) Serum Tg a sensitive marker of thyroid abnormalities and iodine deficiency in epidemiological studies. J Clin Endocrinol Metab 86, 3599-3603.

10. Vejbjerg P, Knudsen N, Perrild H, et al. (2009) Thyroglobulin as a marker of iodine nutrition status in the general population. Eur J Endocrinol 161, 475-481.

11. Zimmermann MB, Aeberli I, Andersson M, et al. (2013) Thyroglobulin is a sensitive measure of both deficient and excess iodine intakes in children and indicates no adverse effects on thyroid function in the UIC range of 100-299 $\mu \mathrm{g} / \mathrm{L}$ : a UNICEF/ICCIDD study group report. J Clin Endocrinol Metab 98, $1271-1280$.

12. Hegedus L, Perrild H, Poulsen LR, et al. (1983) The determination of thyroid volume by ultrasound and its relationship to body weight, age, and sex in normal subjects. J Clin Endocrinol Metab 56, 260-263.

13. Knudsen N, Bols B, Bulow I, et al. (1999) Validation of ultrasonography of the thyroid gland for epidemiological purposes. Thyroid $\mathbf{9}, 1069-1074$.

14. Rasmussen LB, Ovesen L, Bülow I, et al. (2002) Relations between various measures of iodine intake and thyroid volume, thyroid nodularity, and serum thyroglobulin. $A m J$ Clin Nutr 76, 1069-1076

15. Schlumberger M, Fragu P, Gardet P, et al. (1991) A new immunoradiometric assay (IRMA) system for thyroglobulin measurement in the follow-up of thyroid cancer patients. EurJ Nuclear Med 18, 153-157.

16. Haugen BR, Alexander EK, Bible KC, et al. (2016) 2015 American Thyroid Association management guidelines for adult patients with thyroid nodules and differentiated thyroid cancer. The American Thyroid Association guidelines task force on thyroid nodules and differentiated thyroid cancer. Thyroid 26, 1-133.

17. König F, Andersson M, Hotz K, et al. (2011) Ten repeated collections for urinary iodine from spot samples or 24 hour samples are needed to reliably estimate individual iodine status in women. J Nutr 141, 2049-2054.

18. Andersen S, Hvingel B, Kleinschmidt K, et al. (2005) Changes in iodine excretion in 50-69-y-old Denizens of an Arctic society in transition and iodine as a biomarker of the frequency of consumption of traditional Inuit foods. Am J Clin Nutr 81, 656-663.

19. Wilson B \& van Zyl A (1967) The estimation of iodine in thyroidal amino acids by alkaline ashing. $S$ Afr J Med Sci $\mathbf{3 2}$, $70-82$.

20. Laurberg P (1987) Thyroxine and 3,5,3'-triiodothyronine content of thyroglobulin in thyroid needle aspirates in hyperthyroidism and hypothyroidism. I Clin Endocrinol Metab 64, 969-974.

21. Fraser CG \& Harris EK (1989) Generation and application of data on biological variation in clinical chemistry. Crit Rev Clin Lab Sci 27, 409-437.

22. Laurberg P, Bülow Pedersen I, Knudsen N, et al. (2001) Environmental iodine intake affects the type of nonmalignant thyroid disease. Thyroid 11, 457-469.

23. Teng W, Shan Z, Teng X, et al. (2006) Effects of iodine intake on thyroid function in China. $N$ Engl J Med 354, $2783-2793$

24. Hollowell JG, Staehling NW, Hannon WH, et al. (1998) Iodine nutrition in the United States. Trends and public health implications: iodine excretion data from National Health and Nutrition Examination Surveys I and III (1971-1974 and 1988-1994). J Clin Endocrinol Metab 83, 3401-3408.

25. Laurberg P, Jørgensen T, Perrild H, et al. (2006) The Danish investigation on iodine intake and thyroid disease, DanThyr: status and perspectives. Eur J Endocrinol 155, 219-228.

26. Andersen S, Waagepetersen R \& Laurberg P (2015) Misclassification of iodine intake level from morning spot urine samples with high iodine excretion among Inuit and non-Inuit in Greenland. Br J Nutr 113, 1433-1440.

27. Krejbjerg A, Bjergved L, Bulow Pedersen I, et al. (2016) Serum thyroglobulin as a biomarker of iodine deficiency in adult populations. Clin Endocrinol 85, 475-482.

28. Andersen S, Petersen SB \& Laurberg P (2002) Iodine in drinking water in Denmark is bound in humic substances. Eur J Endocrinol 147, 663-670.

29. Andersen S, Guan H, Teng W, et al. (2009) Speciation of iodine in high iodine groundwater in China associated with goitre and hypothyroidism. Biol Trace Elem Res $\mathbf{1 2 8}$, 95-103.

30. Rasmussen LB, Ovesen L, Bülow I, et al. (2002) Dietary iodine intake and urinary iodine excretion in a Danish population: effect of geography, supplements and food choice. Br J Nutr 87, 61-69.

31. Nakamura S, Sakata S, Minamori Y, et al. (1984) Serum thyroglobulin (Tg) concentration in healthy subjects: absence of age- and sex-related differences. Endocrinol Jpn 31, 93-98.

32. Pacini F, Pinchera A, Giani C, et al. (1980) Serum thyroglobulin in thyroid carcinoma and other thyroid disorders. J Endocrinol Invest 3, 283-292.

33. van Herle AJ, Hershman JM, Homabrook RW, et al. (1976) Serum thyroglobulin in inhabitants of an endemic goiter region of New Guinea. J Clin Endocrinol Metab 43, $512-516$.

34. Bayram F, Beyazyildiz A, Gökce C, et al. (2009) The prevalence of iodine deficiency, serum thyroglobulin, antithyroglobulin and thyroid peroxidase antibody levels in the urban areas of Kayseri, Central Anatolia. Exp Clin Endocrinol Diabetes 117, 64-68.

35. Ma ZF \& Skeaff SA (2014) Thyroglobulin as a biomarker of iodine deficiency: a review. Thyroid 24, 1195-1209.

36. Ma ZF, Venn BJ, Manning PJ, et al. (2016) Iodine supplementation of mildly iodine-deficient adults lows thyroglobulin: a randomized controlled trial. J Clin Endocrinol Metab 101, 1737-1744.

37. Feldt-Rasmussen U, Bech K \& Date J (1979) Serum thyroglobulin in patients with toxic and non-toxic goitres compared to sex- and age-matched control subjects. Acta Endocrinol $\mathbf{9 1}$, 264-270

38. Andersen S, Kleinschmidt K, Hvingel B, et al. (2012) Thyroid hyperactivity with high thyroglobulin in serum despite 
sufficient iodine intake in chronic cold adaptation in an Arctic Inuit hunter population. Eur J Endocrinol 166, 433-440.

39. Braverman LE (1996) Evaluation of thyroid status in patients with thyrotoxicosis. Clin Chem 42, 174-178.

40. Gardner DF, Rothman J \& Utiger RD (1979) Serum thyroglobulin in normal subjects and patients with hyperthyroidism due to Graves' disease: effects of T3, iodide, 131I and antithyroid drugs. Clin Endocrinol 11, 585-594.
41. Laurberg P, Andersen S, Bjarnadottir RI, et al. (2007) Evaluating iodine deficiency in pregnant women and young infants - complex physiology with a risk of misinterpretation. Public Health Nutr 10, 1547-1552.

42. Feldt-Rasmussen U, Profilis C, Colinet E, et al. (1996) Human thyroglobulin reference material (CRM 457). 1st Part: assessment of homogeneity, stability and immunoreactivity. Ann Biol Clin (Paris) 54, 337-342. 